\title{
MEDIA PEMBELAJARAN ANALOG OSCILLATOR VIRTUAL LABOLATORY
}

\author{
Aji Widhi Wibowo ${ }^{1)}$, Syifaul Fuada ${ }^{2)}$ \\ 1) Pascasarjana Teknik Mikroelektronika STEI Institut Teknologi Bandung (aji.widhi@gmail.com) \\ 2) Pascasarjana Teknik Mikroelektronika STEI Institut Teknologi Bandung (ㅎyifaul@gmail.com)
}

\begin{abstract}
The purpose of this research is to design and implement a Virtual Labolatory Materials Signal Processing Sub discussion 'Oscillator' Analog as Newspapers. Developers using the model Sutopo Ariesto Hadi (2003) as a method to produce the product. Consists of six stages: concept, design, material collecting, assembly, testing and distribution. This results in the development of Virtual media Labolatory with material 'Oscillator' with the results of 4 (four) practicum digital oscillator, namely (1) Oscillator Wien Bridge, (2) Colpitts oscillator, (3) Oscillator Hartley and (4) astable multivibrator. Another result is that a user be jobsheet practicum. There are two types, namely: (1) jobsheet grip lecturers and (2) jobsheet for students. In Jobsheet there is a short book that contains the Manual on procedures for the use of virtual labolatory when practical and anatomical description of the product. Virtual Labolatory consists of the initial page (flash scren), the main page (home), pages and pages about the developer's lab referring to the story board. There are four (4) test are: (1) the truth polarity capacitor, (2) the connection (wiring), (3) mode frequency and time in the meter frequency counter, (4) Decision special and (5) The quality of the media is seen various aspects
\end{abstract}

Keywords: Analog Oscillator, Virtual Labolatory

\begin{abstract}
Abstrak
Tujuan dari penelitian ini adalah untuk merancang dan mengimplementasikan Virtual Labolatory Materi Pengolahan Sinyal Sub Bahasan 'Oscillator' Analog sebagai PTJJ. Pengembang menggunakan model Sutopo Ariesto Hadi (2003) sebagai metode untuk menghasilkan produk. Terdiri dari 6 tahapan, yaitu concept, design, material collecting, assembly, testing dan distribution. Pengembangan ini menghasilkan media Virtual Labolatory dengan materi 'Oscillator' dengan hasil 4 (empat) praktikum oscillator secara digital, yakni (1) Oscillator Wien Bridge, (2) oscillator Colpitts, (3) Oscillator Hartley dan (4) Astable Multivibrator. Hasil lain adalah berupa jobsheet yang merupakan petunjuk praktikum. Terdapat dua jenis yakni: (1) jobsheet pegangan dosen dan (2) jobsheet untuk mahasiswa. Dalam Jobsheet terdapat Manual book singkat yang berisi tentang tata cara penggunaan virtual labolatory saat praktikum dan penjelasan anatomi produk. Virtual Labolatory ini terdiri dari halaman awal (flash scren), halaman utama (home), halaman praktikum dan halaman tentang pengembang yang mengacu pada story board. Terdapat 4 (empat) pengujian yakni: (1) Kebenaran polaritas kapasitor, (2) penyambungan (wiring), (3) mode frequency dan time pada alat ukur frequency counter, (4) Decision khusus dan (5) Kualitas media dipandang berbagai aspek.
\end{abstract}

Kata Kunci : Oscillator Analog, Virtual Labolatory

\section{PENDAHULUAN}

Sinyal sangat erat kaitannya dengan peranan pembangkit sinyal, pembangkit sinyal atau disebut Oscilator adalah sebuah rangkaian atau alat yang digunakan untuk membangkitkan keluaran berbentuk gelombang dengan bentuk dan frekuensi tertentu. Secara definisi oscilator merupakan rangkaian elektronik yang didesain sebagai pembangkit sinyal, menurut pembagiannya sinyal dibagi menjadi dua macam yakni Oscilator Sinusoidal/Harmonic dan Oscilator Relaksasi. Dalam sistem elektronika oscilator merupakan salah satu bagian yang terpenting. Aplikasinya sangat kompleks misalnya saja sebagai (1) osilator lokal untuk 
mengubah sinyal RF ke sinyal IF pada sistem receiver; (2) untuk menghasilkan RF carrier pada sistem pemancar, (3) untuk menghasilkan clock (pencacah waktu (timer) dalam sistem digital; (4) konversi gelombang penyearah (Direct Curret) ke gelombang bolak-balik (Alternating Current) dan lain-lain.

Mengingat kompleksitas dan urgensi sistem pembangkit sinyal ini, menjadikan oscilator sebagai suatu keharusan untuk dikuasai mahasiswa teknik elektronika. Permasalahan paling umum, untuk mempraktekkan rangkaian oscillator mahasiswa tidak dapat melakukannya di luar labolatorium. Karena harus menguji dengan alat osciloscope dan frequency counter yang mana harus dipergunakan didalam labolatorium mengingat harga yang mahal dan tidak diperkenankan di pinjam untuk diuji coba dirumah.

Untuk membantu mahasiswa belajar dibutuhkan media yang memuat materi tentang oscillator yang terintegrasi labolatorium digital. Peneliti telah merancang sistem Virtual labolatory dengan materi oscillator analog. Virtual Labolatory adalah proses pembelajaran elektronik dengan menggunakan simulasi computer (admin, 2015). Pengembangan media ini memiliki potensial untuk memberikan peningkatan secara signifikan dan pengalaman belajar yang lebih efektif. Manfaat yang dapat diperoleh adalah proses pembelajaran menjadi lebih menarik dan interaktif, jumlah waktu mengajar dapat dikurangi, kualitas belajar dapat ditingkatkan dan proses belajar mengajar dapat dilakukan di mana dan kapan saja.

Beberapa manfaat yang dapat diperoleh dari virtual labolatory ini adalah: (1) Mengurangi keterbatasan waktu, jika tidak ada cukup waktu untuk mengajari seluruh peserta didik di dalam lab hingga mereka paham; (2) Ekonomis, tidak membutuhkan bangunan lab, alat-alat dan bahan-bahan seperti pada laboratorium konvensional; (3) Meningkatkan efektivitas pembelajaran, karena peserta didik akan semakin lama menghabiskan waktunya dalam lab virtual tersebut berulang-ulang, dan (4) Meningkatkan keamanan dan keselamatan, karena tidak berinteraksi dengan alat dan sengatan listrik yang nyata.

Diharapkan dengan virtual labolatory mampu mengatasi berbagai persoalan, seperti jarak, waktu, biaya, dan terbatasnya sumber daya pengajar, dan terutama beragamnya kecepatan belajar mahasiswa. Secara khusus tujuan pengembangan ini adalah untuk merancang dan mengimplementasikan Virtual Labolatory Materi Pengolahan Sinyal Sub Bahasan 'Oscillator' Analog sebagai PTJJ.

Penulis mengusulkan sebuah virtual labolatory oscillator. Media ini adalah praktikum oscillator secara digital. Terdapat 4 (empat) praktikum yang telah dibuat, yakni (1) praktikum oscillator Wien Bridge, (2) praktikum oscillator Colpitts, (3) praktikum oscillator Hartley dan (4) Praktikum Astable Multivibrator. Media dibuat secara offline berbasis desktop. Pengoperasian media ini dengan mengganti R/L/C kemudian melakukan aktivitas plug and play dari R-C ke tool kit dan hasil dapat dilihat pada alat ukur frequency counter.

\section{METODE}

\section{A. Model Pengembangan}

Pengembang menggunakan model Sutopo Ariesto Hadi (2003) sebagai metode untuk menghasilkan produk Virtual Labolatory. Pengembang memilih model ini karena pertimbangan sebagai berikut: (1) sifatnya sederhana dan terstruktur secara sistematis, menjadikan model ini mudah untuk dipelajari dan memudahkan pendesain mengaplikasikan langkah-langkah dari model ini, (2) konsepnya yang sederhana tapi mewakili keseluruhan sistem proses pembelajaran, dan (3) strukturnya yang sistematis, sehingga tidak membingungkan pendesain dalam merancang sistem pembelajaran. Terdiri dari 6 tahapan, yaitu concept, design, material collecting, assembly, testing dan distribution. 


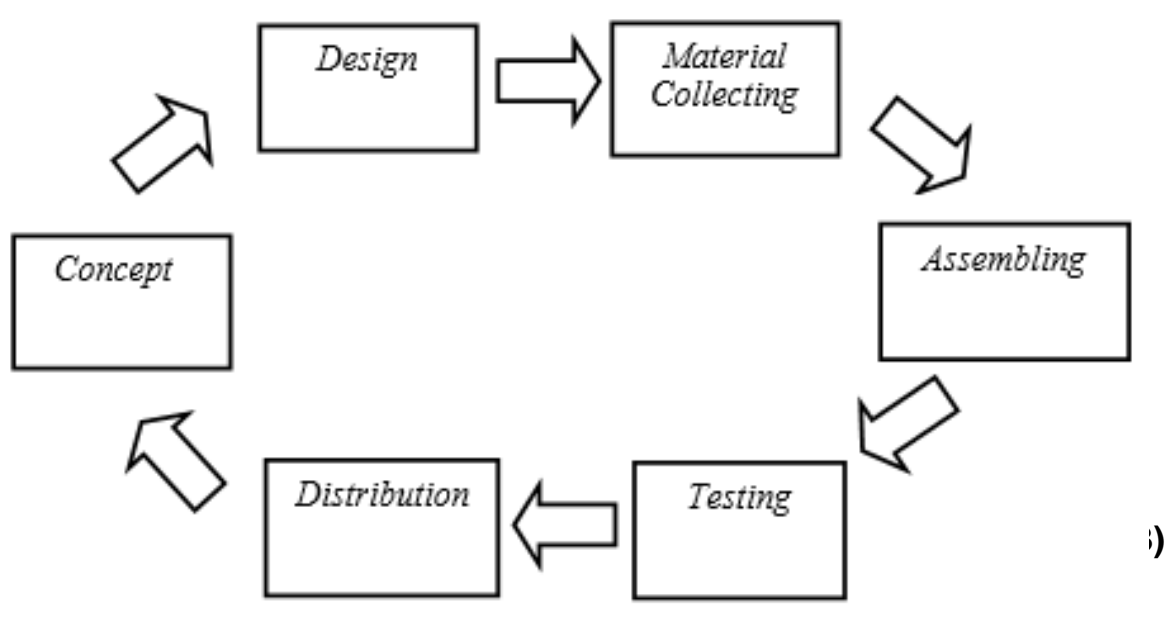

Gambar 1 Metode Pengembangan

\section{B. Prosedur Penelitian \\ a. Concept}

Aplikasi yang diusulkan merupakan aplikasi perangkat lunak tentang virtual labolatory dengan materi oscilator analog. Desain disajikan secara 2 dimensi yang ditampilkan pada dekstop. Aplikasi yang akan dibuat hanya untuk melakukan praktikum, yakni praktikum (1) Oscilator Wien Bridge. (2) Oscilator Hartley; (3) Oscilator Colpitts dan (5) Astable Multivibrator. Pendahuluan (prasyarat, tujuan dan tutorial), Materi lengkap dari 4 oscillator yang dikembangkan serta Evaluasi tersedia dalam jobsheet yang terpisah dari Virtual Labolatory. Sebelum melakukan praktikum, seorang praktikan dianjurkan untuk membaca jobsheet.

Pada window praktikum, tool kit, layar osciloskop dan frekuensi generator telah disediakan sehingga praktikan mengoperasikan aplikasi ini dengan melakukan aktivitas plug and play dari ke tool kit ke modul Resistor/ Kapasitor/ Induktor. Praktikan melihat besaran frekuensi dan time yang dihasilkan melalui alat ukur yang telah disediakan.

Disini penyambungan modul R/L/C ke tool kit ditentukan (tergantung oleh tabel pengukuran yang terdapat didalam jobsheet). Dengan demikian praktikan tidak dapat melakukan plug and play secara coba-coba karena praktikum harus dilakukan berdasar pada teori. Setelah melakukan praktikum, praktikan diharuskan untuk menganalisa hasil praktikum yang selanjutnya ditulis dalam laporan praktikum. Terakhir, praktikan wajib untuk melakukan evaluasi diri dengan menjawab soal-soal yang tersedia di modul.

\section{b. DESIGN}

\section{(a) Spesifikasi kebutuhan perangkat lunak}

Sebelum menentukan kebutuhan perangkat keras, tentunya harus diperhatikan aplikasi yang akan digunakan dalam proses pengembangan. Berikut ini spesifikasi kebutuhan perangkat lunak yang digunakan selama proses pengembangan pada penelitian ini.

- Sistem Operasi : Windows 8

- Animation Developer : Adobe Flash CS6

- Grafik Editor : CorelDraw X6, Photoshop CS6

- Pembuatan tool kits : Microsoft Visio 2007

\section{(b) Spesifikasi kebutuhan perangkat keras}

Berikut ini adalah spesifikasi perangkat keras yang digunakan dalam penelitian ini.

- Processor dan Memory: Pentium Core i3 dan 4 GB DDR2

- VGA : Onboard (1 GB)

- Resolution requirement : 64 Bit 


\section{(c) Properti}

- Background : meja praktikum

- Alat ukur : frequency counter mode frequency dan time

- Peralatan praktikum : jumper secara virtual dan power supply yang dioperasikan secara on dan off (tanpa aktivitas jumpering)

- Alat peraga praktikum : Oscilator Wien Bridge, Oscilator Hartley, Oscilator Colpitts, Astable Multivibrator, Modul Resistor $1 \mathrm{~K} \Omega, 10 \mathrm{~K} \Omega, 2 \mathrm{~K} \Omega, 20 \mathrm{~K} \Omega, 3 \mathrm{~K} \Omega$ \& $30 \mathrm{~K} \Omega$, Modul Kapasitor 10nF, 100nF, 1 uF, $10 \mathrm{uF}, 100 \mathrm{uF} \& 100 \mathrm{uF}$, Modul Induktor 10H \& 5H

\section{(d) Audio}

Penggunaan audio dalam vitual lab ini terdapat dalam setiap aktivitas plug and play, yakni: suara aktivitas penyambungan antar properti, suara on-off power supply maupun penggantian mode frequency ke mode time atau sebaliknya pada frequency counter, suara button memilih praktikum dan tombol close serta Yes/no.

\section{Material Collecting}

Pada tahap ini, pengembang melakukan pembuatan bahan-bahan yang terkait dengan virtual labolatory ini. Pencarian logo SEAMOLEC dan ITB dilakukan di google, foto-foto pengembang, penyusunan biografi pengembang, penulisan deskrisi media dan Penggunaan sound. Sound tidak dibuat sendiri melainkan memakai sound yang telah tersedia di google dengan syarat tanpa watermark.

\section{Assembling}

Pada tahap ini tim membuat Virtual Labolatory dengan materi oscillator analog, pembuatan tool kits masing-masing oscillator beserta modul RLC menggunakan Microsoft Visio 2007, sedangkan Grafik Editor menggunakan program CorelDraw Xsuite dan Photoshop CS6. Programming dilakukan di Adobe Flash CS6. Virtual Labolatory yang dibuat ini didasarkan pada penggabungan unsur pengetahuan dengan unsur kesenangan dalam melakukan praktikum.

\section{E. Distribution}

Virtual labolatory bersifat offline pada desktop, maka dari itu dalam distribusinya dapat di upload pada suatu web sehingga mahasiswa dapat mengunduh dan melakukan praktikum secara mandiri dimanapun berada. pendistribusian media ini juga dapat dilakukan dengan cara sederhana yakni melalui Compact Disk atau Flask Disk.

\section{HASIL PENGEMBANGAN DAN PEMBAHASAN}

\section{A. Hasil Pengembangan Produk}

Hasil pada penelitian ini adalah Virtual Labolatory materi oscillator analog, yakni (1) Oscillator Wien Bridge, (2) oscillator Colpitts, (3) Oscillator Hartley dan (4) Astable Multivibrator. Hasil lain adalah berupa jobsheet yang merupakan petunjuk praktikum. Terdapat dua jenis yakni: (1) jobsheet pegangan dosen dan (2) jobsheet untuk mahasiswa. Dalam Jobsheet terdapat Manual book singkat yang berisi tentang tata cara penggunaan virtual labolatory saat praktikum dan penjelasan anatomi produk.

Virtual Labolatory ini terdiri dari halaman awal (flash scren), halaman utama (home), halaman praktikum dan halaman tentang pengembang. Pembuatan Virtual Labolatory ini mengacu pada story board, hasilnya adalah sebagai berikut:

\section{a. Halaman awal (flash screen)}

Tampilan halaman flash screen selalu muncul pada awal user membuka aplikasi. Isi dari halaman awal ini adalah copyright developer (CSyifaul Fuada, S.Pd \& Aji Widhi W, S.Kom), sponsor dan tahun pendanaannya yakni SEAMOLEC tahun 2015, serta logo afiliasi pengembang dan sponsor yakni ITB dan SEAMOLEC. Kemudian keluar tombol "masuk", praktikan harus menekan tombol "masuk" untuk menuju pilihan praktikum oscillator. 


\section{b. Halaman Utama (Home)}

Halaman utama berisi pilihan praktikum yang terdiri dari (1) Oscillator Wien Bridge, (2) Oscillator Colpitts, (3) Oscillator Hartley dan (4) Astable Multivibrator, serta profil tentang pengembang. Apabila menu ini diklik akan merujuk pada lembar kerja praktikum oscillator,

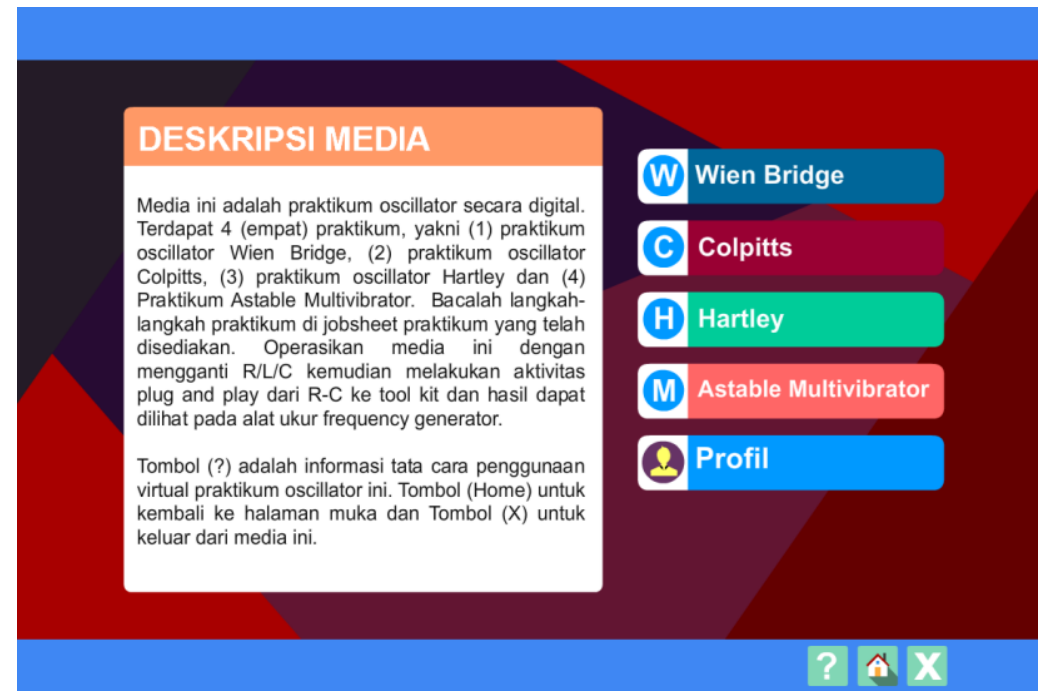

Gambar 2 Tampilan Halaman Utama (Home)

\section{c. Halaman Praktikum secara Virtual}

Pada halaman muka misalnya seorang praktikan menekan tombol Wien bridge, maka yang muncul adalah meja kerja Wien Bridge seperti yang ditampilkan pada Gambar 3 merupakan Meja kerja dari Oscilator Wien Bridge.

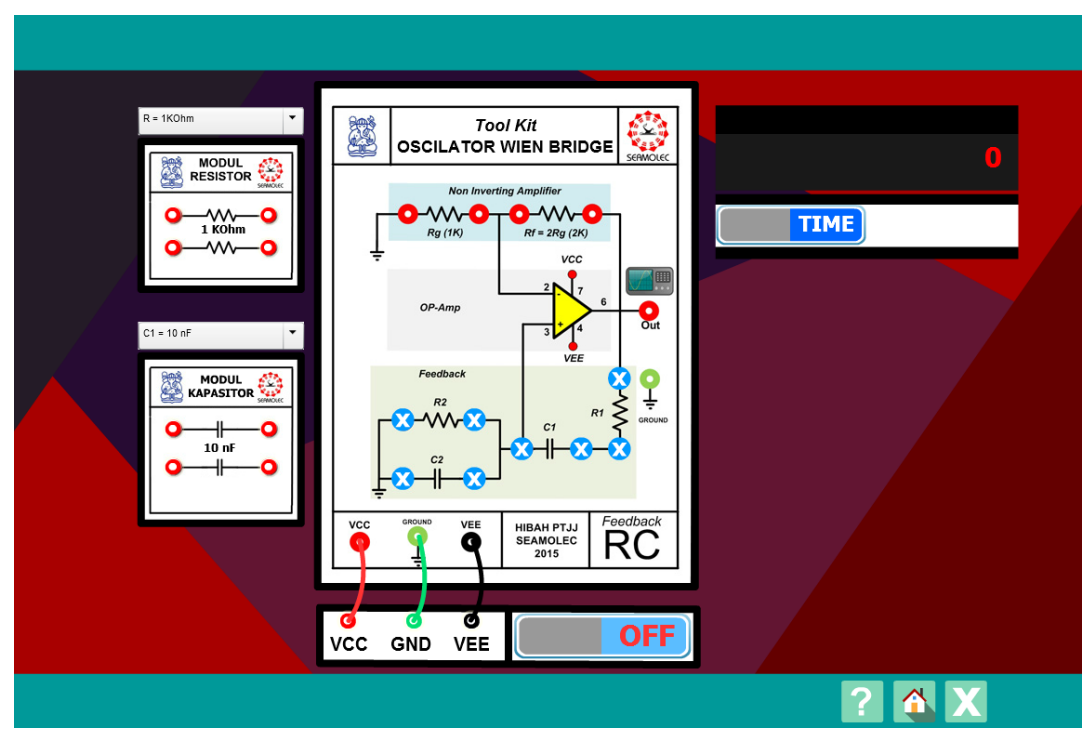

Gambar 3. Tampilan Halaman Praktikum Oscillator

Modul Oscilator telah disediakan langsung pada meja kerja, sehingga pengguna hanya memilih R/C pada menu "Modul R" dan "Modul C". Setelah dipilih R/C, praktikan melakukan aktivitas plug and play kemudian melihat hasil dari pengukuran frequency counter. Begitu halnya dengan tombol-tombol praktikum yang lainnya.

\section{d. Halaman tentang Pengembang}

Halaman ini akan muncul apabila tombol "profil" di klik. Halaman ini menampilkan tim yang merancang produk virtual labolatory ini. 


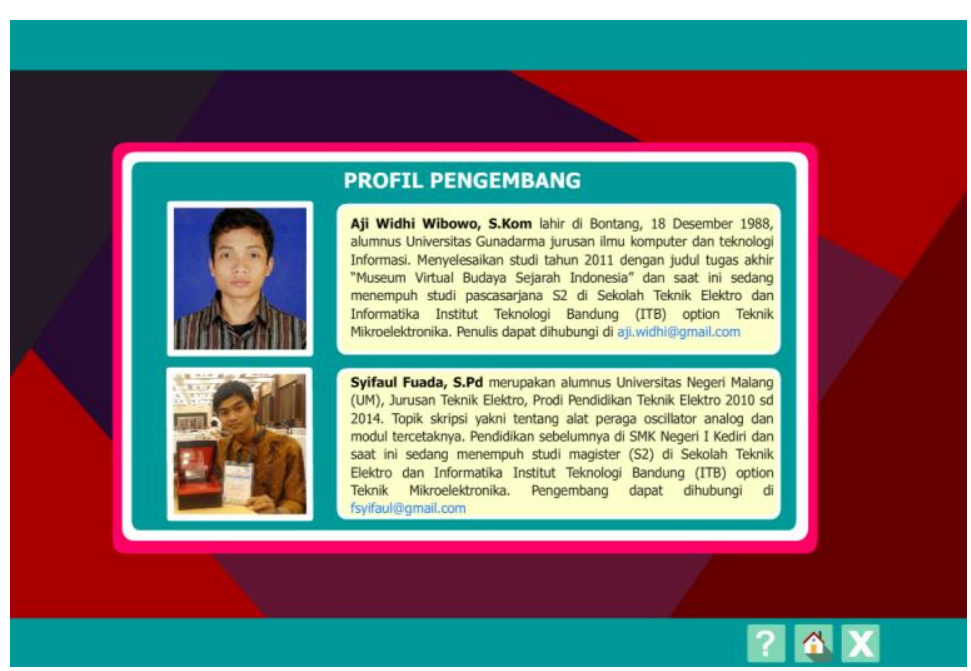

Gambar 4 Tampilan Halaman Tentang Pengembang

\section{B. Pengujian Produk}

Pengujian kualitas media ini meliputi kualitas suara, teks, warna latar belakang, kemudahan dioperasikan, tata letak dan lain sebagainya. Lebih detal dinyatakan dalam tabel 2

\section{Tabel 1. Tabel Pengujian Oscillator Virtual Labolatory}

\begin{tabular}{|c|c|c|}
\hline Variabel & Cheklist & Keterangan \\
\hline Kualitas sound & Baik & $\begin{array}{l}\text { Penggunaan sound dalam vitual lab ini } \\
\text { terdapat dalam setiap aktivitas plug and play, } \\
\text { button memilih praktikum dan tombol close } \\
\text { serta Yes/no. Semuanya berkualitas baik. }\end{array}$ \\
\hline Teks & Baik & $\begin{array}{l}\text { Teks yang terdapat pada vitual lab ini jelas } \\
\text { terbaca, ukuran dan warna teks tepat serta } \\
\text { pemilihan font tepat. }\end{array}$ \\
\hline $\begin{array}{l}\text { Warna latar } \\
\text { belakang dari } \\
\text { virtual labolatory }\end{array}$ & Baik & $\begin{array}{l}\text { Warna latar belakang tepat, nyaman } \\
\text { dipandang, tidak timpang terhadap warna } \\
\text { tool kits sehingga tidak mengganggu saat } \\
\text { pelaksanaan praktikum. }\end{array}$ \\
\hline $\begin{array}{l}\text { Kemudahan } \\
\text { intruksi }\end{array}$ & Baik & $\begin{array}{l}\text { Kalimat disusun dengan Bahasa yang } \\
\text { sederhana tidak berbelit-belit (to the point) } \\
\text { disertai symbol-simbol terkait sehingga } \\
\text { intruksi mudah dipahami }\end{array}$ \\
\hline $\begin{array}{l}\text { Kesesuaian } \\
\text { dengan story board }\end{array}$ & Baik & $\begin{array}{l}\text { Hasil Virtual labolatory sesuai dengan } \\
\text { perencanaan dalam story board }\end{array}$ \\
\hline Kejelasan gambar & Baik & $\begin{array}{l}\text { Gambar-gambar pada Virtual labolatory } \\
\text { seperti tool kits, modul RLC, tombol-tombol } \\
\text { disajikan dengan high resolution. }\end{array}$ \\
\hline $\begin{array}{l}\text { Kemudahan } \\
\text { pengoperasian }\end{array}$ & Baik & $\begin{array}{l}\text { Virtual labolatory mudah dioperasikan dan } \\
\text { telah disediakan intruksi apabila terdapat } \\
\text { kendala dalam praktikum }\end{array}$ \\
\hline $\begin{array}{l}\text { Ketepatan tata } \\
\text { letak }\end{array}$ & Baik & $\begin{array}{l}\text { Tata letak Tool kits, modul RLC, menu-menu } \\
\text { pada Virtual labolatory sehingga } \\
\text { memudahkan navigasi dan tidak } \\
\text { membingungkan praktikan/pengguna. }\end{array}$ \\
\hline Kapasitas & Baik & $\begin{array}{l}\text { Kapasitas virtual labolatory yakni } 8,4 \mathrm{MB} \text {, } \\
\text { tidak memakan memori yang besar. Aplikasi } \\
\text { ini ringan dijalankan sehingga RAM tidak } \\
\text { over }\end{array}$ \\
\hline compability & Baik & $\begin{array}{l}\text { virtual labolatory ini dapat dioperasikan } \\
\text { dengan baik (tidak debug) dalam berbagai } \\
\text { jenis computer dengan syarat terdapat } \\
\text { program flash player }\end{array}$ \\
\hline
\end{tabular}




\section{KESIMPULAN}

Telah dirancang dan dibuat sebuah media Virtual Labolatory dengan materi 'Oscillator' dengan hasil 4 (empat) praktikum oscillator secara digital, yakni (1) Oscillator Wien Bridge, (2) oscillator Colpitts, (3) Oscillator Hartley dan (4) Astable Multivibrator. Hasil lain adalah berupa jobsheet yang merupakan petunjuk praktikum. Terdapat dua jenis yakni: (1) jobsheet pegangan dosen dan (2) jobsheet untuk mahasiswa. Dalam Jobsheet terdapat Manual book singkat yang berisi tentang tata cara penggunaan virtual labolatory saat praktikum dan penjelasan anatomi produk. Virtual Labolatory ini terdiri dari halaman awal (flash scren), halaman utama (home), halaman praktikum dan halaman tentang pengembang yang mengacu pada story board. Kualitas media yang meliputi kualitas sound, teks, warna latar belakang, kemudahan intruksi, kesesuaian dengan story board, kejelasan gambar, kemudahan pengoperasian, tata letak, kapasitas dan kompabilitas. Hasil secara keseluruhan adalah baik sehingga virtual labolatory ini sudah dapat digunakan.

\section{SARAN}

\section{Saran Pemanfaatan}

Model pembelajaran yang digunakan sebaiknya adalah Contextual Teaching and Learning (CTL) agar praktikan dapat memaknai pengetahuan berdasarkan pengalaman belajar mereka.

\section{Saran Pengembagan Produk}

a. Perlu adanya video tutorial sehingga lebih mempermudah pelaksanaan praktikum serta perlu adanya pilihan musik pengiring yang slow pada virtual labolatory sehingga membuat praktikan nyaman dan tidak mudah bosan.

b. Virtual labolatory didalamnya perlu integrasi dengan Pendahuluan, Materi yang disajikan secara teks dan animasi, jobsheet serta alat evaluasi yang generate secara acak sehingga menjadikan virtual labolatory lebih praktis.

c. Perlu adanya system evaluasi agar siswa dapat lebih tertarik menggunakan buku ajar dengan media yang berbeda dan menarik.

d. Perlu ditambahkan dengan alat ukur oscilloscope pada Virtual labolatory sehingga praktikan dapat melihat frekuensi yang dihasilkan oleh masing-masing oscillator dalam bentuk sinyal.

e. Perlu ditambahkan oscillator yang lebih banyak seperti oscillator kristal, twin-T, clapps dan jenis-jenis oscillator analog lain sehingga Virtual labolatory lebih bervariasi.

\section{DAFTAR PUSTAKA}

Admin. Virtual Labolatory Definition. diakses di http://www.gunadarma.ac.id/en/page/virtual-lab.html pada 25 April 2015

Asad, S.M. 2012. Oscillators. EEET 201 - Chapter 16. E-Modul diakses di http://www.hbcc.edu.sa/facpages/SyedMuhammadAsad/Data files/EEET\%20201/Ch16.p df pada 10 Maret 2014

Faradina, Ines. 2015. Sinyal Gadgetmu Lemah? Alat Temuan Mahasiswa ini Bisa Mengatasinya. Diakses di www.brilio.net. pada 5 April 2015

Ferdinando, H. 2010. Dasar-dasar Sinyal \& Sistem. Yogyakarta: Penerbit Andi

Fuada, S. 2013. Analisis Oscilator Astable Multivibrator IC 741UA Menggunakan Pendekatan Matlab dan Software Elektronik. Prosiding SENTIA 2013-Politeknik Negeri Malang Volume 5. Hal. A54-A60

Fuada, S. 2014. Pengujian Trainer Oscilator Wien Bridge (Jembatan Wien) dengan Menggunakan Osciloskop dan Frekuensi Counter. Prosiding SENTIA 2014-Politeknik Negeri Malang, Volume 6. HIm. A32-A36

Fuada, S. 2014. Pengembangan Trainer Pembangkit Sinyal (Oscilator) di Jurusan

Teknik Elektro Fakultas Teknik Universitas Negeri Malang (UM). Skripsi Jurusan Teknik Elektro Fakultas Teknik UM, Skripsi tidak diterbitkan 
Hadi, S.A. 2003. Multimedia Interaktif dan Flash. Yogyakarta: PT Graha ilmu. Yogyakarta.

Mancini, R. 2000. Design of OP AMP sine wave oscillators. Analog Applications Journal on August 2000, Hal: 35. Texas Instruments Incorporated

Muchlas. 2014. Pengembangan V-Lab Menggunakan Aplikasi Online Meeting dan Simulator Breadboard untuk Praktikum Elektronika Digital. Prosiding Pertemuan IImiah XXVIII HFI Jateng \& DIY, Yogyakarta, 26 April 2014.

Nova Amalia Latif, dkk. 2009. Pengembangan E-Laboratory Untuk Praktikum Elektronika Pada Mahasiswa Pendidikan Fisika Universitas Ahmad Dahlan. Prosiding Seminar Nasional Penelitian, Pendidikan dan Penerapan MIPA, FMIPA, UNY, 16 Mei 2009. Hal. F69-F74

Sapto H, dkk. 2013. Integrating Virtual Laboratory From Conventional Lab Into Vocational High School to Facilitate Practicum Activity. Proceeding Seminar on Electrical, Informatics, And Its Education. HIm. A45-A51 